\title{
Effect of wick structure geometry on the performance of a heat pipe
}

\author{
Dr. Hussain H.Ahmad \\ College of Engineering \\ University of Mosul
}

\author{
Raqeeb H. Rajab \\ College of Agriculture\& forestry \\ University of Mosul
}

\begin{abstract}
A mathematical model was set up to find the heat transfer coefficient in a heat pipe with a grooved wick structure having axial capillaries of different cross sections through producing a considerable capillary pressure forced and hydraulic drag. From this viewpoint a model is developed and solved analytically to estimate the heat pipe performance. A different geometry groove shapes in the inside surface of a heat pipe are designed. From the proposed model, numerical optimization is performed to enhance the thermal performance of the heat pipe for measuring the maximum heat transport rate. The exact pressure drop and the temperature drop calculations were performed using finite element modeling by Ansys program. Also, in the present study comparison between various geometry groove shapes with same depth (circular, trapezoidal and rectangular) at constant wall heat flux condition is made including the effect of the groove shapes on the heat transfer characteristics in a turbulent tube flow ( Reynolds number range 5000-15000). The analytical result for the maximum heat transport rate was obtained when the geometry is circular while the rectangular grooved pipe is decreased by (20)\% in comparison with the circular grooved pipes.
\end{abstract}

Key Words: Heat pipes, wick structure, groove.

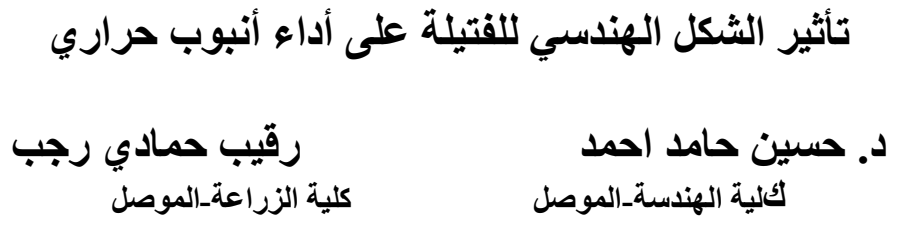

الخلاصة

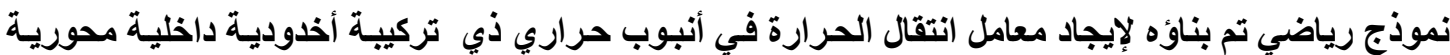

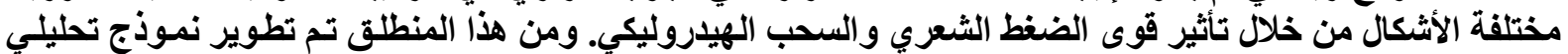

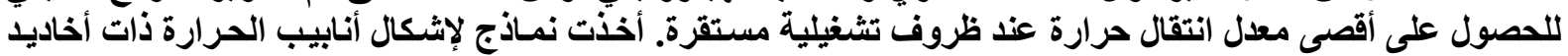

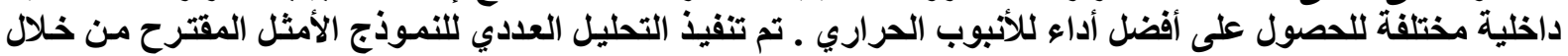

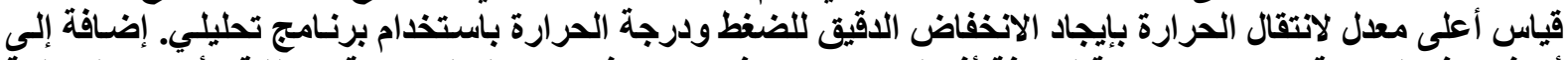

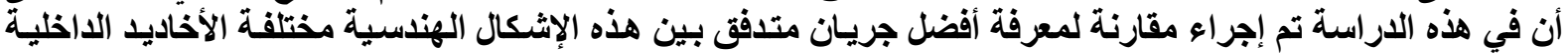

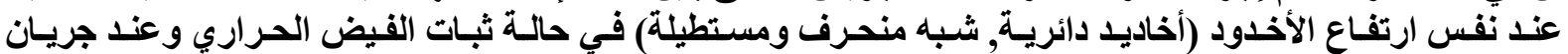

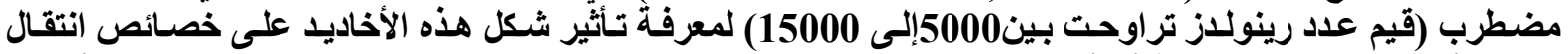

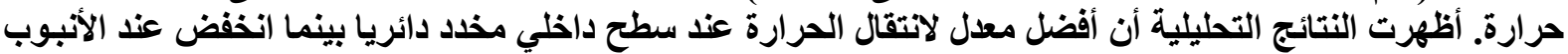

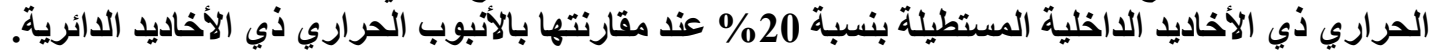




\section{Nomenclature}

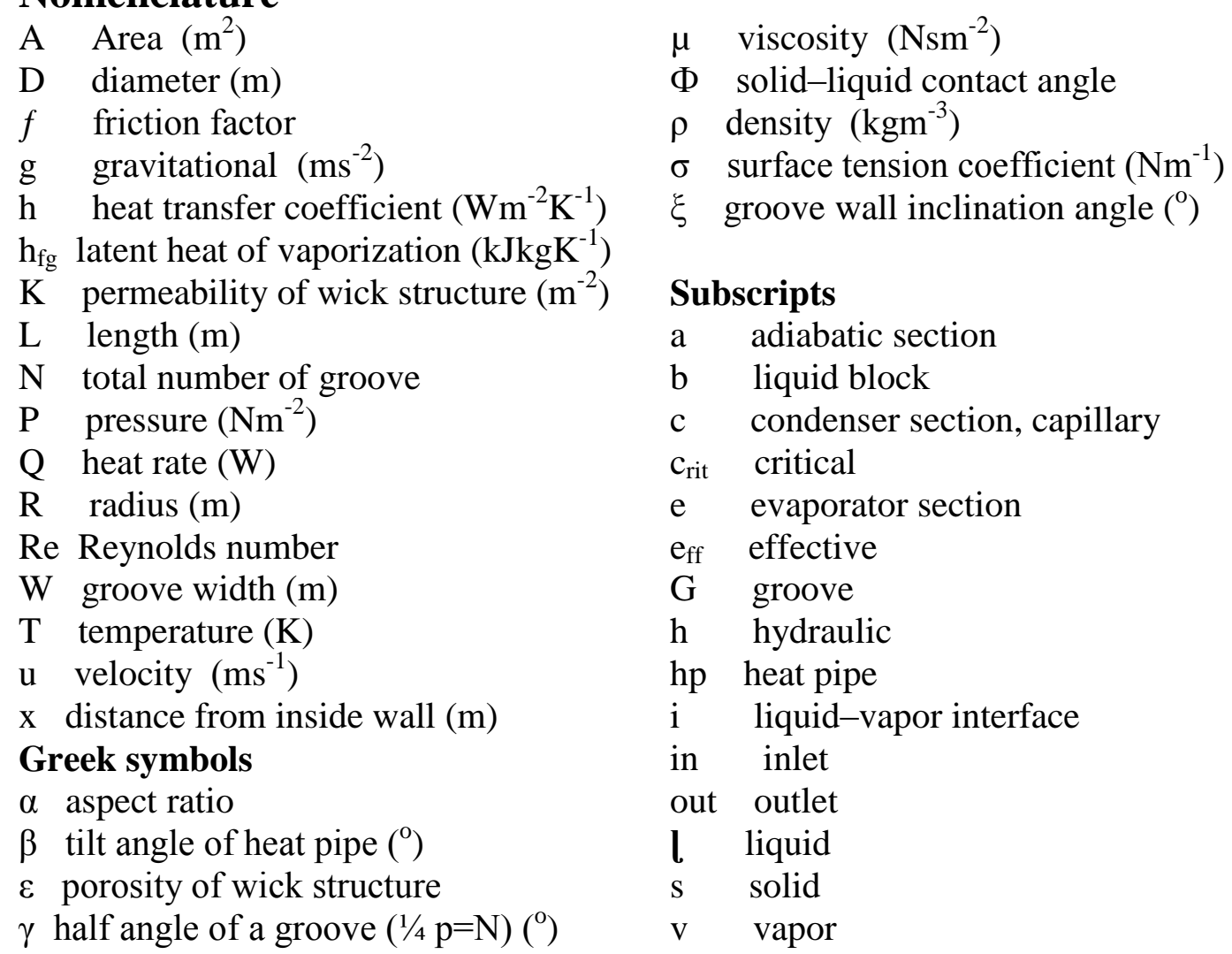

\section{1- Introduction}

The grooved heat pipe technology has proven its efficiency in the thermal control of highly dissipative equipment's such as electronic components of satellites, chemical machine construction and other branch of industry. Among conventional heat pipes, grooved heat pipes are often used for spacecraft thermal regulation as they offer a high capillary pumping action. As power increases and size reduction is constantly asked in the space industry, geometric optimization of the designed product appears as a real challenge for industrials involved with this technology. Use of the articulate grooved or a fluted tube is widely used in modern heat exchangers because they are very effective in heat transfer augmentation. Therefore, many industries active in the space domain show an interest to develop numerical tools allowing for sizing, characterization or the risk failure prediction of the heat pipes and avoiding a too large amount of experiments.

The capacity of the wick to ensure the required mass flow velocity of the liquid heat-transfer agent is one of the factors limiting the maximum heat flux through the pipe. Oomi et al. [1] investigated the maximum heat transport rate of miniature heat pipes with a grooved wick structure using an experimental method disregarding the heat loss in the experimental apparatus. San and Huang [2] experimentally investigated the heat transfer enhancement of transverse ribs in circular tubes. Stroes et al. [3] experimentally investigated the capillary forced in the channels with different sections. Khrustalev and Faghri [4] developed a numerical model for heat and mass transfer characteristics occurring in a micro heat pipe with triangular grooves. Webb et al. [5] investigated the heat transfer and fluid friction for fully developed turbulent flow in tubes with transverse ribs. The tubes were arranged with a constant surface heat flux condition. A set of correlations of Stanton number and friction factor was obtained. The heat transfer in a circular tube with a slat-like blockage was investigated by Sparrow et al. [6]. The heat transfer enhancement was found to be 
effective within a distance of 10 tube diameters downstream of the blockage. Kiml et al. [7] studied the angled ribs mounted on the inner surface of a tube with an angle between the plane of each rib and the mean flow direction for different angles and the transverse ribs. Goto et al. [8,9] investigated the condensation and evaporation augmentations in internally grooved tube. The measured data yield a set of Nusselt number correlations. All inserts were inserted into the tube by wall attached position. They behave like ribs or fins on the inner surface of the tube. The mechanism of heat transfer enhancement by the inserts is based on the flow separation and reattachment and gives the swirl effect to the fluid flow through the tube. There are numerous investigations using the periodic and fully developed concepts on fluid flow and heat transfer for the parallel plate channels with periodically grooved parts. Ghaddar et al.[10], Sunden and Trollheden [11] and Pereira and Sousa [12] investigated the flow in channels with rectangular grooves.

A few papers have been published to study the effect of the geometry groove shapes on the heat transfer characteristics in a turbulent tube flow. So, numerical studies of surface heat transfer characteristics of a fully developed turbulent flow in different axially grooved shapes geometric (circular, trapezoidal and rectangular) at the same grooved height with different heat input has been conducted in this work.

\section{Fundamentals of heat pipe operation}

Heat pipe is a closed tube whose inner surface is lined with a grooved channel as shown in figure (1). The wick structure geometry is saturated with the liquid phase of a working fluid and the remaining volume of the tube contains vapor phase.

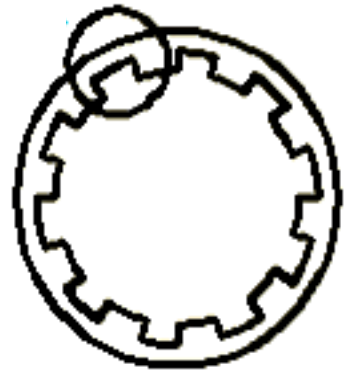

Section A3-A3 Rectangular groove

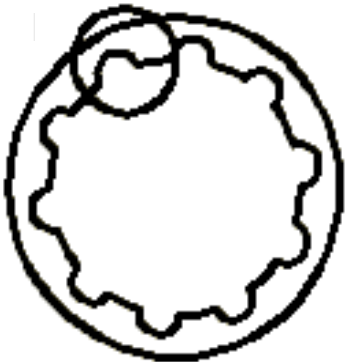

Section A 2-A2

Circular groove

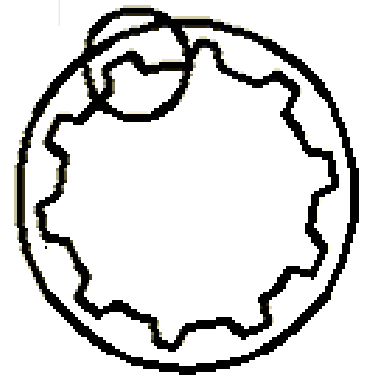

Section A1-A1

Trapezoidal groove

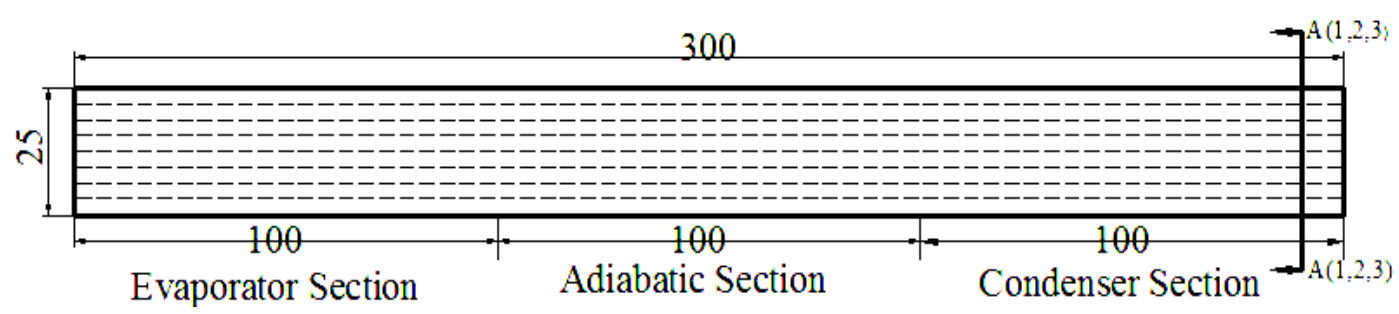

Figure (1): operation of a heat pipe

Heat applied at the evaporator by an external source vaporizes the working fluid in that section. The resulting difference in pressure drives vapor from the evaporator to the condenser where it condenses releasing the latent heat of vaporization to a heat sink in that section of the pipe. Circulation of working fluid is an important heat pipe factor. So, the 
maximum possible circulation is required to obtain the maximum heat transport capability of the grooved channel heat pipe.

Forced convection heat transfer is the most frequently employed mode of the heat transfer in heat pipes. The use of the turbulence promoters or roughness elements, such as welded ribs or grooves on the surface, is a common technique to enhance the rate of heat transfer. A commonly used technique for improving the performance of heat pipe devices is to set up periodic disturbance promoters along the stream wise direction. Such an arrangement of channels lead to the enhancement of the heat transfer due to flow mixing and periodic interruptions of thermal boundary layers, but often causes an increase of pressure drop penalty.

\section{Mathematical Formulation}

\subsection{Theoretical Analysis}

A theoretical model for flow and heat transfer in a heat pipe with axially grooved is developed and calculated numerically to achieve the maximum heat transfer capability.

The following main assumptions are made for the present mathematical model:

1. Steady-state operation is considered.

2. Heat flux along the channel is uniform.

3. The liquid phase is assumed to be continuous.

4. The flow is assumed to be turbulent.

5. The transport of non-condensable inside the grooved pipe is neglected.

6. Ideal gas law is assumed to be valid for the vapor phase

7. Two-dimensional channel flow is considered.

8. Working fluids wets completely the wall.

Specifications of the heat pipe used in the proposed model are shown in Table 1.

\begin{tabular}{|l|l|}
\hline $\mathrm{D}_{\text {out }}(\mathrm{mm})$ & 25 \\
\hline Number of groove $(\mathrm{N})$ & 10 \\
\hline Vapor core radius $\left(\mathrm{R}_{\mathrm{v}}\right)(\mathrm{mm})$ & 0.75 \\
\hline Groove depth $(\mathrm{H})(\mathrm{mm})$ & 2 \\
\hline Groove width $(\mathrm{W})(\mathrm{mm})$ & 4 \\
\hline Groove bottom width $(\mathrm{W} / 2)(\mathrm{mm})$ & 2 \\
\hline Pitch between grooves $(\mathrm{P})(\mathrm{mm})$ & 4 \\
\hline Wall thickness $(\mathrm{mm})$ & 4 \\
\hline Working fluid & Water \\
\hline Initial amount of liquid charge $(\mathrm{g})$ & 20 \\
\hline Solid material & Copper \\
\hline Evaporator section length $(\mathrm{mm})$ & 100 \\
\hline Adiabatic section length $(\mathrm{mm})$ & 100 \\
\hline Condenser section length $(\mathrm{mm})$ & 100 \\
\hline Working temperature $\left({ }^{\circ} \mathrm{C}\right)$ & 100 \\
\hline Power input $(\mathrm{W})$ & $100-250$ \\
\hline
\end{tabular}

Table (1): Specifications (geometric parameters) of the grooved heat pipe

As shown in Figure (2), a liquid droplet at rest on a solid surface surrounded by a pure vapor is considered. The droplet system has three interfaces, one between the solid and vapor, another between the solid and liquid, and the third one between the liquid and vapor. Three 
surface tensions exist in these interfaces and satisfy the Young's equation under static equilibrium in the horizontal direction $[13,15]$

$$
\sigma_{\mathrm{sv}}=\sigma_{\mathrm{sl}}+\sigma_{\mathrm{lv}} \cos \Theta
$$

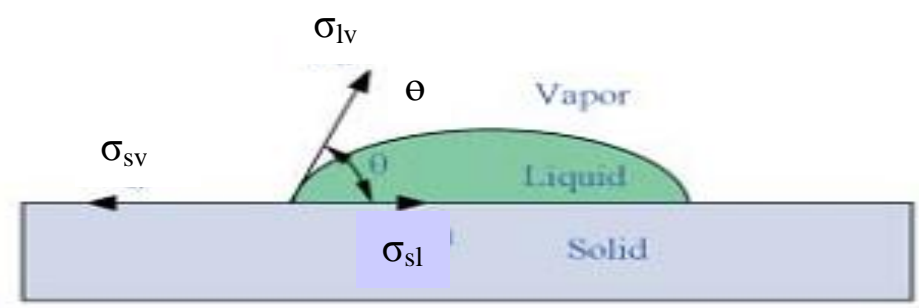

Figure (2): A single drop at rest on a solid surface surrounded by a pure vapor

Where $\theta$ is contact angle which represents a macroscopic wetting characteristics. When liquid is in contact with a solid surface, one of three conditions is possible at equilibrium: complete wetting $(\theta=0)$, partial wetting $(0<\theta<90)$, or non-wetting $(\theta>90)$. In Eq. $(1), \sigma_{\mathrm{sv}}, \sigma_{\mathrm{sl}}$ and $\sigma_{\mathrm{lv}}$ are interfacial tensions between solid-vapor, solid-liquid and liquidvapor, respectively. The interfacial tension between liquid-vapor is generally called as surface tension that decreases with increasing temperature. As $\theta$ decreases, the liquid spreads more over the solid surface. Equation (1) can be rearranged to the form,

$\cos \theta=\frac{\sigma_{\mathrm{sv}}-\sigma_{\mathrm{sI}}}{\sigma_{\mathrm{Iv}}}$

The surface tensions between these interfaces can be expressed by the Helmholtz free energy [14]

$\frac{\mathrm{dE}}{\mathrm{dA}_{\mathrm{ij}}}$

Where; $\mathrm{A}_{\mathrm{ij}}$ represents the interfacial area and $\mathrm{i}=\mathrm{s}, \mathrm{v}, \mathrm{l}$

Hence, the change in Helmholtz free energy between three interfaces can be written as $\mathrm{dE}=\sigma_{\mathrm{lv}} \mathrm{dA}_{l \mathrm{v}}+\sigma_{\mathrm{sl}} \mathrm{dA}_{\mathrm{sl}}+\sigma_{\mathrm{sv}} \mathrm{dA}_{\mathrm{sv}}$.

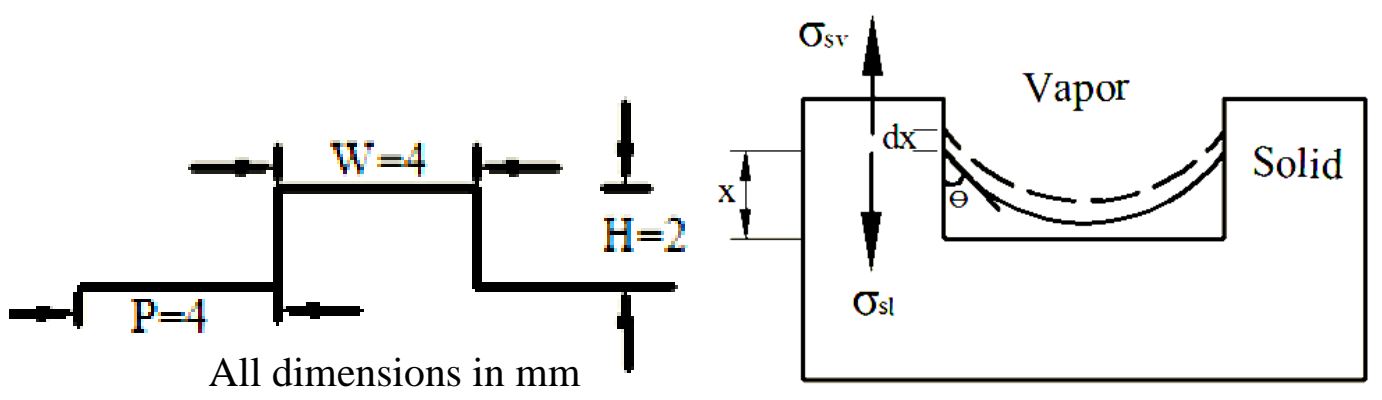

Figure (4): Capillary phenomena in a rectangular groove.

As shown in Figure (4), a groove with a rectangular cross-sectional area is placed in the vertical direction and its bottom end is inserted in the liquid. Assuming that the initial height of water in the groove is $(\mathrm{x})$ and the capillarity of groove pulls the water forward a distance $(\mathrm{dx})$, the area changes of the liquid-vapor, solid-liquid and solid-vapor interface can be expressed as

$\mathrm{dA}_{\mathrm{lv}}=\mathrm{Wdx}$,

$\mathrm{dA}_{\mathrm{sl}}=(2 \mathrm{H}+\mathrm{W}) \mathrm{dx}=(2 \mathrm{~W}) \mathrm{dx}$,

$\mathrm{dA}_{\mathrm{lv}}=-(2 \mathrm{H}+\mathrm{W}) \mathrm{dx}=-(2 \mathrm{~W}) \mathrm{dx}$, 
Where; $(\mathrm{W})$ the width and $(\mathrm{H})$ is the height of groove that equal half of the width. The meniscus front effect of liquid is neglected here. Substituting Eqs. (5-7) into Eq.(3) and combining with Eq. (1),

The change in the Helmholtz free energy dE is [14] $\mathrm{dE}=\sigma_{\mathrm{lv}} \times[\mathrm{W}-(2 \mathrm{~W}) \cos \theta] \mathrm{dx}$.

The capillary force $\left(\mathrm{F}_{\mathrm{c}}\right)$ applied on the liquid column along the vertical direction can be obtained by taking the derivative of the Helmholtz free energy with respect to $\mathrm{x}$ [14], that is,

$\mathrm{F}_{\mathrm{c}}=-\mathrm{dE} / \mathrm{dx}=\sigma_{\mid \mathrm{v}} \times[(2 \mathrm{~W}) \cos \theta-\mathrm{W}]$

The capillary pressure $\left(\mathrm{P}_{\mathrm{c}}\right)$ is equal to the capillary force $\left(\mathrm{F}_{\mathrm{c}}\right)$ divided by the cross-sectional area of groove $[15,16]$

$\mathrm{Pc}=\sigma_{\mathrm{lv}}[(4 \mathrm{~W}) \cos \Theta-2 \mathrm{~W}] / \mathrm{W}^{2}$

To calculate the height of liquid column, the diagram as shown in Figure (4) is considered. The forces acted on the liquid column are the capillary fore $\mathrm{F}_{\mathrm{c}}$ (upward) and gravitational force $\mathrm{F}_{\mathrm{g}}$ (downward). As the static equilibrium is reached and the height of liquid column is equal to $\mathrm{H}$, we have

$\mathrm{F}_{\mathrm{c}}=\mathrm{F}_{\mathrm{g}}$, is $[17,18]$

Here the capillary force $\left(\mathrm{F}_{\mathrm{c}}\right)$ is shown in Eq. $(9)$ and the gravitational force $\left(\mathrm{F}_{\mathrm{g}}\right)$

$$
\begin{aligned}
& F_{g}=m_{l} \times g=\rho_{l} \times g \times W^{2} / 2, \\
& H=\sigma_{l v}[(4 W) \cos \theta-2 W] / \rho_{l} \times g \times W^{2}
\end{aligned}
$$

\subsection{Pressure and temperature drop analysis}

The groove geometry of the inner surface of the heat pipe has a considerable effect on the pressure drop in the channel. The geometry of the rectangular design was numerically modeled as shown in the Figure (5) to study the effect of porosity on the pressure drop. The bottom face resembling the wick was divided into 10000 face areas. The porosity in the wick was varied by varying the number of faces with velocity inlet boundary conditions in the bottom face of the channel. The pressure drop was numerically calculated using Fluent program.

Calculation of pressure drop and temperature drop was very essential determination of optimal various grooves geometry. The pressure drop for each design was approximately calculated using a simple 2D channel principle. In a fully developed, steady state turbulent flow with no slip condition and assuming constant fluid properties, the pressure $\operatorname{drop}(\Delta \mathrm{P})$ of the rectangular channel flow can be predicted as shown as[19]:

$$
\Delta \mathrm{P}=\mathrm{f} \frac{\mathrm{L}}{\mathrm{D}_{\mathrm{h}}} \frac{\rho \mathrm{U}^{2}}{2}=\mathrm{fRe} \frac{\mu \mathrm{L}}{\rho \mathrm{UD}_{\mathrm{h}}^{2}} \frac{\rho \mathrm{U}^{2}}{2}
$$

Where Darcy's friction factor (f) [20],

$$
\mathrm{f}=\frac{2 \mathrm{D}_{\mathrm{h}}}{\rho \mathrm{U}^{2}}\left(-\frac{\mathrm{dp}}{\mathrm{dx}}\right)
$$

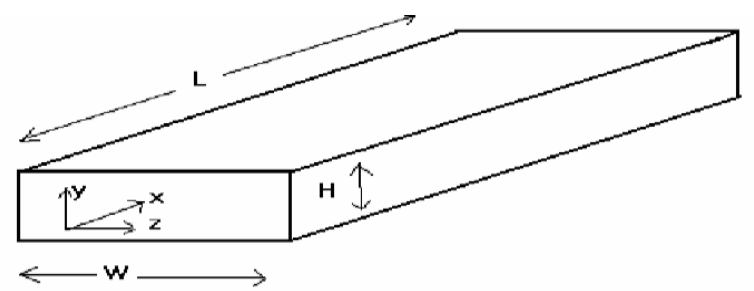

Figure (5): Rectangular grooved shape 
(L) is the $\mathrm{x}$-directional length along the channel and $(\mathrm{U})$ is the mean velocity of the fluid in the channel with cross sectional area $\left(\mathrm{A}_{\mathrm{G}}\right)$.mean fluid velocity is defined as

$\mathrm{U}=\mathrm{m} / \rho \times \mathrm{A}_{\mathrm{G}}$

Hydraulic diameter is given by,

$\mathrm{D}_{\mathrm{h}}=\frac{4(\text { cross sectional area })}{\text { wetted perimeter }}=\frac{2 \mathrm{WH}}{\mathrm{W}+\mathrm{H}}=\frac{2}{3} W$

The total liquid pressure $\operatorname{drop}\left(\Delta \mathrm{P}_{\ell}\right)$ can be determined by integrating the pressure gradient over the length of the flow passage, $[15,21]$ or

$$
\Delta \mathrm{P}_{1}(\mathrm{x})=-\int_{0}^{\mathrm{L}} \frac{\mathrm{dp}}{\mathrm{dx}} \mathrm{dx}
$$

where the limits of integration are from the evaporator end $(x=0)$ to the condenser end $(\mathrm{x}=\mathrm{L})$ and $\mathrm{dP}_{1} / \mathrm{dx}$ is the gradient of the liquid pressure resulting from the frictional forces of the solid wick, wall, and vapor flow at the liquid-vapor interface, and can be written as

$$
\frac{\mathrm{dp}_{1}}{\mathrm{dx}}=\left(\frac{\mu_{1}}{\mathrm{~K} \times \mathrm{A}_{\mathrm{G}} \times \rho_{1}}\right) \dot{\mathrm{m}}_{1}
$$

When a meniscus is formed at the liquid-vapor interface as shown in Figure(3), the capillary pressure $\left(\mathrm{P}_{\mathrm{c}}\right)$ can be calculated by the well-known Laplace-Young equation $[16,18]$

$$
\mathrm{P}_{\mathrm{c}}=\mathrm{P}_{\mathrm{v}}-\mathrm{P}_{1}=\sigma\left(\frac{1}{\mathrm{r}_{\mathrm{c} 1}}+\frac{1}{\mathrm{r}_{\mathrm{c} 2}}\right)
$$

Where $\left(r_{c 1}\right)$ and $\left(r_{c 2}\right)$ are the principal capillary radii of the meniscus at liquid phase and vapor phase respectively. Since $r_{c 2}$ is much larger than $r_{c 1}$, it is quite reasonable to assume that $\mathrm{rc}_{1}=\mathrm{rc}(\mathrm{x})$ and $\mathrm{r}_{\mathrm{c} 2}=\infty$. The deferential form of Eq. (19) then becomes

$\frac{\mathrm{dp}_{\mathrm{v}}}{\mathrm{dx}}-\frac{\mathrm{dp}_{1}}{\mathrm{dx}}=-\frac{\sigma}{\mathrm{r}_{\mathrm{c}}(\mathrm{x})^{2}} \frac{\mathrm{dr}_{\mathrm{c}}(\mathrm{x})}{\mathrm{dx}}$

If we express the liquid and vapor pressure gradient terms in Eq.(20) using geometric variables and the capillary radius, Eq.(20) can be solved numerically. By modeling the grooved wick structure in Figure(1) as a porous medium, the liquid pressure gradient can be expressed by $[17,19]$

$\frac{\mathrm{dp}_{1}}{\mathrm{dx}}=-\frac{\mu_{1} \mathrm{u}_{\mathrm{D}}}{\mathrm{K}}$

This is known as Darcy's law. Using the relationship between the Darcian velocity $\left(u_{D}\right)$ and the averaged pore velocity $\left(u_{p}\right)$, porosity of wick structure $\varepsilon=u_{D} / u_{p}$, and the mass flow rate in the wick structure,

$$
\begin{aligned}
& \mathrm{m}_{\mathrm{l}}=\rho \times \mathrm{A}_{\mathrm{p}} \times \mathrm{u}_{\mathrm{p}} \times \mathrm{N} \quad ; \quad \text { Equation (21) becomes: } \\
& \frac{\mathrm{dp}_{1}}{\mathrm{dx}}=-\frac{\mu_{1} \varepsilon \mathrm{u}_{\mathrm{p}}}{\mathrm{K}}=-\frac{\mu_{1} \varepsilon \dot{\mathrm{m}}_{1}}{\rho_{1} \mathrm{~A}_{\mathrm{p}} \mathrm{NK}}
\end{aligned}
$$

$\mathrm{K}$; the permeability of a groove with different cross-section, can be written as [17]

$$
\mathrm{K}=\frac{\mathrm{D}_{\text {in }}^{2} \times \varepsilon}{2 \times \mathrm{fRe}_{\mathrm{hp}}}
$$

The product of the friction factor and Reynolds number ( $\mathrm{fRe}_{\mathrm{hp}}$; the coefficient of drag). However, the liquid flow passage of a heat pipe to the vapor core region where vapor flows in the direction opposite to the liquid flow. These counter-flow of liquid and vapor cause an additional shear stress at the liquid-vapor interface, which makes analysis of the liquid flow difficult. The effect of the counter-flow on the interfacial shear stress can be 
accounted for by introducing a correction factor, $\alpha$, when substituting Eq.(23) into Eq.(22), which results in the following Eqs.[15,17]:

$\frac{\mathrm{dp}_{1}}{\mathrm{dx}}=-\frac{2 \mu_{1} \mathrm{fRe}_{\mathrm{hp}} \dot{\mathrm{m}}_{1}}{\rho_{1} \mathrm{~A}_{\mathrm{p}} \mathrm{ND}_{\mathrm{in}}^{2}} \alpha+\rho_{1} \mathrm{gsin} \beta$

The last term included in the right side of Eq. (24) is for a pressure drop due to gravity, in the coefficient of drag ( $\left(\mathrm{Re}_{\mathrm{hp}}\right)$, the aspect ratio $(\alpha)$, the liquid flow area $\left(\mathrm{A}_{l}\right)$ and the mass flow rate of liquid $\left(\mathrm{m}_{l}\right)$, need to be expressed in terms of the geometric variables and thermo-physical properties of the liquid in order to quantitatively evaluate the liquid pressure gradient.

The coefficient of drag ( $\mathrm{fRe}_{\mathrm{hp}}$ ) for the different geometry channels [15,17 ]:

$$
f \operatorname{Re}_{h p}=G_{w}\left(1-1.3553 \alpha+1.9467 \alpha^{2}-1.7012 \alpha^{3}+0.9564 \alpha^{4}-0.2537 \alpha^{5}\right)
$$

Where;

$\alpha=$ Aspect ratio; $\alpha=\frac{H}{W}$

$\mathrm{G}_{\mathrm{w}}=$ Geometry coefficient;

The present analytical study results gives:

$\mathrm{G}_{\mathrm{w}}=52,39,23$ for the circular, trapezoidal and rectangular channels respectively.

To evaluate the ratio of the actual liquid pressure drop with the counter flow effect included to the ideal liquid pressure drop with no vapor flow effect, as in Eq. (24), iterative calculations are needed and the entire calculation procedure can be summarized as follows (a primed variable denotes that it is affected by non-zero vapor flow), the correlations of $\left(\mathrm{fRe}_{\mathrm{h} ; \mathrm{p}}\right)$ with a various contact angles, for a function of the geometric variables and the contact angle.

For a trapezoidal open channel, the contact angle is taken into account as shown in figure (6).

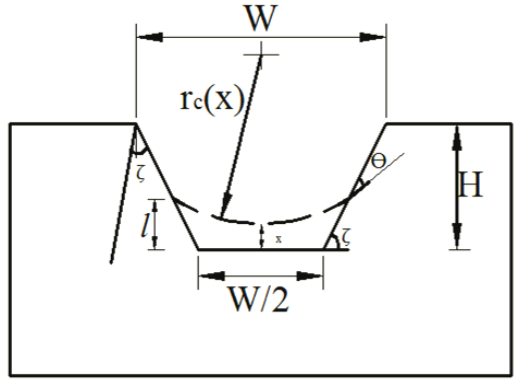

Figure (6): Schematic diagram of the trapezoidal groove.

Which is an interfacial property of the solid-liquid pair (the grooved wall and liquid) an actual liquid flow area below the meniscus,

$\mathrm{A}_{\mathrm{l}}$, can be written for $\mathrm{r}_{\mathrm{c}} \leq \mathrm{r}_{\text {crit }}$ as [22 ]

$$
\mathrm{A}_{1}=\mathrm{r}_{\mathrm{c}}(\mathrm{x}) \cos \lambda\left\{2 \ell+\mathrm{r}_{\mathrm{c}}(\mathrm{x}) \sin \beta\right\}-\ell^{2} \tan (\zeta-\gamma)-\mathrm{r}_{\mathrm{c}}(\mathrm{x})^{2}\left\{\frac{\pi}{2}-\lambda\right\}
$$

Where

$$
\begin{aligned}
& \lambda=(\theta+\zeta-\gamma) \quad \text { and } \quad \ell=\frac{2 \mathrm{r}_{\mathrm{c}}(\mathrm{x}) \cos (\theta+\xi-\gamma)-\mathrm{W}}{2 \tan (\theta+\xi-\gamma)}, \\
& \mathrm{r}_{\mathrm{c}, \text { crit }}=\frac{\mathrm{W}[1+\tan (\xi-\gamma)]}{2 \cos (\theta+\xi-\gamma)}
\end{aligned}
$$

On the other hand, for $\boldsymbol{r}_{\boldsymbol{c}} \geq \boldsymbol{r}_{\text {c.crit }}$, [22]

$$
\left.\mathrm{A}_{\mathrm{p}}=\frac{\mathrm{W}^{2}}{2}\left\{\frac{1}{2} \tan (\xi-\gamma)+1\right\}-\frac{1}{2} \mathrm{r}_{\mathrm{c}}{ }^{2}(\eta-\sin \eta)\right\}
$$




$$
\eta=2 \sin ^{-1}\left\{\frac{\mathrm{W}[1+\tan (\xi-\gamma)]}{2 \mathrm{r}_{\mathrm{c}}}\right\}
$$

And $r_{c, \text { crit }}$ is defined as a critical capillary radius beyond which the radius of curvature for the meniscus cannot increase without changing the given contact angle. In other words, $r_{c}$ becomes $r_{c, \text { crit }}$ when (1) in Eq.(27) equals $(H)$, as shown in Figure (6). The mass flow rate of liquid $\left(\mathrm{m}_{l}\right)$ which is the final information required to determine the liquid pressure gradient, can be obtained from the energy balance at each section as:

$\dot{m}_{l}=-\dot{m}_{v}=-\frac{Q(x)}{h_{f g}}$

$\mathrm{h}_{\mathrm{fg}} ;$ Latent heat of vaporization,

$\mathrm{m}_{\mathrm{l}} \& \mathrm{~m}_{\mathrm{v}}$; mass flow rate of liquid and vapor respectively.

For the heat flow $\mathrm{Q}_{\mathrm{t}}$, that heat travels through two parallel paths: one is through the groove fin and then through a microfilm region formed at the liquid-fin interface and the other is directly through the liquid in the groove. In that case, the heat flux and the heat transfer coefficient in the following Equation:

$$
\begin{aligned}
& q_{\text {in }}=\frac{Q(x)}{L_{e}}=N Q_{t}=h \times N \times\left(T_{s}-T_{v}\right) \\
& h=\frac{N \times Q_{t}}{N \times\left(T_{s}-T_{v}\right)}
\end{aligned}
$$

$\mathrm{Q}_{\mathrm{t}}$ : The heat flow that travels through two parallel paths

In the present study, it is assumed that a uniform heat flux is applied at the evaporator (condenser) section for heating (cooling). Note that the present model includes the effect of a liquid block. Because the thermal conductivity of the liquid block length is much lower than that of the solid wall, $\left(\mathrm{L}_{\mathrm{b}}\right)$ the liquid block length acts as a thermal barrier for the condensation heat transfer. Accounting for the liquid block length, heating and cooling conditions can be expressed as follows [15,23]:

$$
Q(x)=\left\{\begin{array}{l}
\frac{\mathrm{x}}{\mathrm{L}_{\mathrm{e}}} \mathrm{Q}_{\text {in }}, \quad 0 \leq \mathrm{x} \leq \mathrm{L}_{\mathrm{e}} \\
\mathrm{Q}_{\text {in }}, \quad \mathrm{L}_{\mathrm{e}} \leq \mathrm{x} \leq \mathrm{L}_{\mathrm{e}}+\mathrm{L}_{\mathrm{a}} \\
\left(1+\frac{\mathrm{Le}+\mathrm{La}-\mathrm{x}}{\mathrm{L}_{\text {eff }, \mathrm{c}}}\right) \mathrm{Q}_{\text {in }}, \\
\mathrm{L}_{\mathrm{e}}+\mathrm{L}_{\mathrm{a}} \leq \mathrm{x} \leq \mathrm{L}_{\mathrm{e}}+\mathrm{L}_{\mathrm{a}}+\mathrm{L}_{\text {eff }}
\end{array}\right.
$$

Where; $\quad \mathrm{L}_{\mathrm{eff}, \mathrm{c}}=\mathrm{L}_{\mathrm{c}}-\mathrm{L}_{\mathrm{b}}$

Assuming the vapor as an ideal gas, we can calculate $\mathrm{P}_{\mathrm{v}}(\mathrm{x})$ at $\mathrm{x}=0$,

Using the ideal gas law and combining Eqs. (20,24 and 31) yields an ordinary differential equation for $r_{c}(x)$ as $[15,17,19]$ :

$$
\frac{\mathrm{dr}_{\mathrm{c}}(\mathrm{x})}{\mathrm{dx}}=\frac{\mathrm{r}_{\mathrm{c}}(\mathrm{x})^{2}}{\sigma}\left[\left(\frac{2 \mu_{1} \mathrm{~m}_{1} \mathrm{fRe}_{\mathrm{h}, \mathrm{p}}}{\rho_{1} \mathrm{~A}_{\mathrm{p}} \mathrm{ND}_{\mathrm{h}, \mathrm{p}}{ }^{2}} \alpha+\rho_{1} \mathrm{gsin} \beta\right)-\frac{\mathrm{dP}_{\mathrm{v}}}{\mathrm{dx}}\right]
$$


Using Eqs. (25-31), the correlations of $\mathrm{fRe}_{\mathrm{hp}}$ and Eq. (32) can be cast into the following form of which the left-hand side is a function of several parameters:

$$
\frac{\mathrm{dr}_{\mathrm{c}}(\mathrm{x})}{\mathrm{dx}}=\mathrm{f}\left(\mathrm{r}_{\mathrm{c}}(\mathrm{x}), \mathrm{Q}_{\mathrm{in}}, \mathrm{T}_{\mathrm{s}, \mathrm{v}}, \theta, \text { geometry, } \dot{\mathrm{m}}\right)
$$

Once all the variables are specified, Eq. (32) can be solved numerically using the fourth-order Runge-Kutta method. Note that all the thermo-physical properties are assumed to be constant and evaluated at the working temperature of the heat pipe.

In solving Eq. (33), an initial value of $r_{c}(x)$ at $x=0$. If a heat pipe is to transport a maximum amount of heat, a minimum capillary radius should be formed at the beginning of the evaporator section and a maximum capillary radius at the point where the liquid block starts in the condenser section [14]. In this situation, the minimum capillary radius can be evaluated from the groove geometry as in Eq. (34), which is used as the initial condition for $r_{c}(x)$ at $x=$ 0 for Eq. (33).

$$
r_{c}=\frac{\mathrm{W}}{2[\cos (\theta+\xi-\gamma)-\tan (\xi-\gamma)\{1-\sin (\theta+\xi-\gamma)\}]}
$$

For simple flow passages with the various geometry groove shapes (circular, trapezoidal and rectangular), the velocity field and pressure distributions can be derived using an analytic method (fourth-order Runge-Kutta). By using the Engineering Equation Solver (EES) and the conventional (CFD) programs. Computational Fluid Dynamics (CFD) is a computer-based tool for simulating the behavior of systems involving heat transfer and other related physical processes. It works by solving the equations of fluid flow over a region of interest, with specified conditions on the boundary of that region. Moreover, the characteristics of counter-current flows make it even more complicated and require much effort and computational time.

\section{Results and discussion:}

Computational Fluid Dynamics Program was used to determine the exact pressure drop in the various geometry groove shapes. The present results can offer the necessary information in the design of optimal geometry shape. Figure (7) represents the liquid and vapor pressure and capillary radius distributions along the axial different geometry groove shapes (circular, trapezoidal and rectangular) of the heat pipe which is obtained from the mathematical model. Figure (7a) shows that the capillary radius increases on-linearly along the axial direction and begins to increase quickly at the starting of the condenser section. This implies that the deference in the pressure slope between the liquid and the vapor begins to decrease quickly at the condenser section because the capillary radius is inversely proportional to the pressure deference between the liquid and vapor.

The pressure drop in the channel was found to be $(100 \mathrm{kPa})$ for $(150 \mathrm{~W})$ power as shown in Figure $(7 \mathrm{~b})$. This pressure drop in the vapor phase along the axial direction on heat pipe was very small compared to that in the liquid phase. 
Ahmad: Effect of wick structure geometry on the performance of a heat pipe
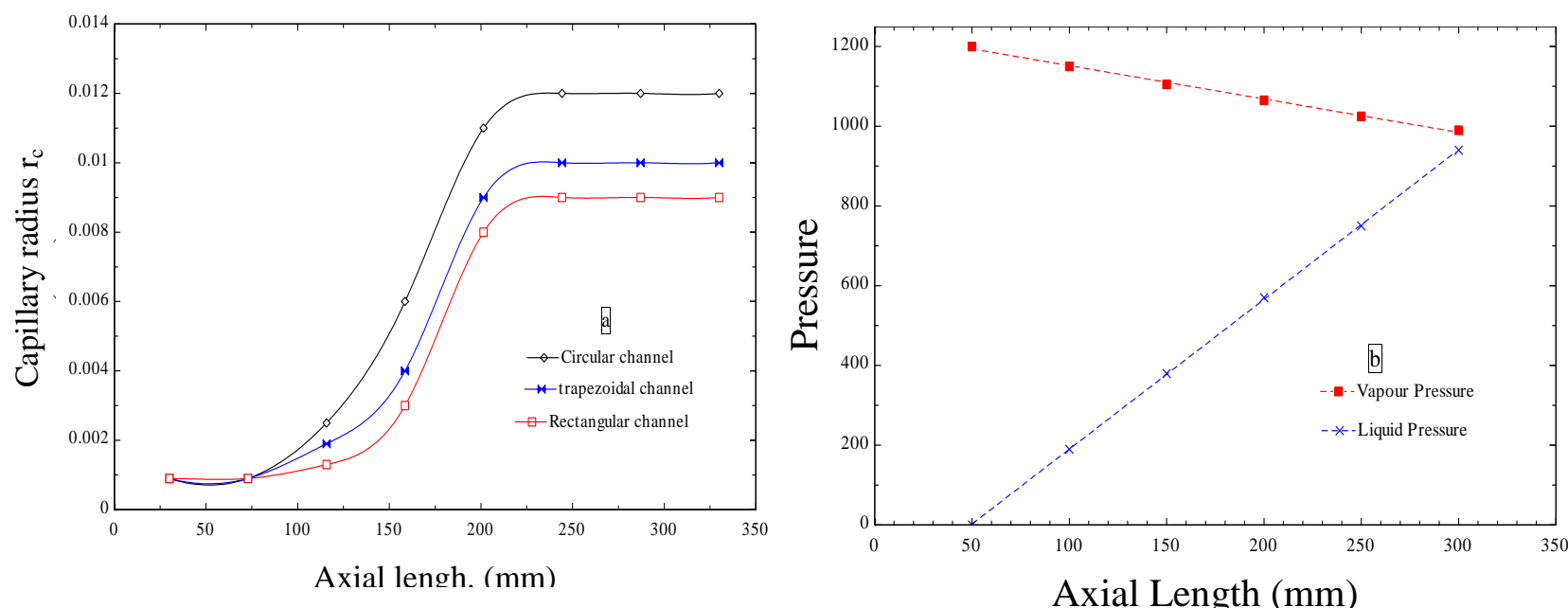

Figure (7): Liquid and vapor pressure and capillary radius distributions along the axial length of the HP.(a)Liquid and vapor pressure distributions (b)Capillary radius distribution

Figure (8) depicts the variation of friction coefficient of inside surface wall with Reynolds number for different groove shapes. Friction coefficients of all grooved pipe have nearly small difference. The friction factor decreases slowly with increase of Reynolds number. It can be said it's independed of Reynolds number. This figure shows that the rectangular grooved wick heat pipe has very small value higher than the friction factor in comparison with both the circular and trapezoidal grooved pipes respectively because of it's sharp corner edges.

Figure (9) shows that the circular groove shape has the highest performance compared to the other geometry shapes. This is due to the lowest friction factor.

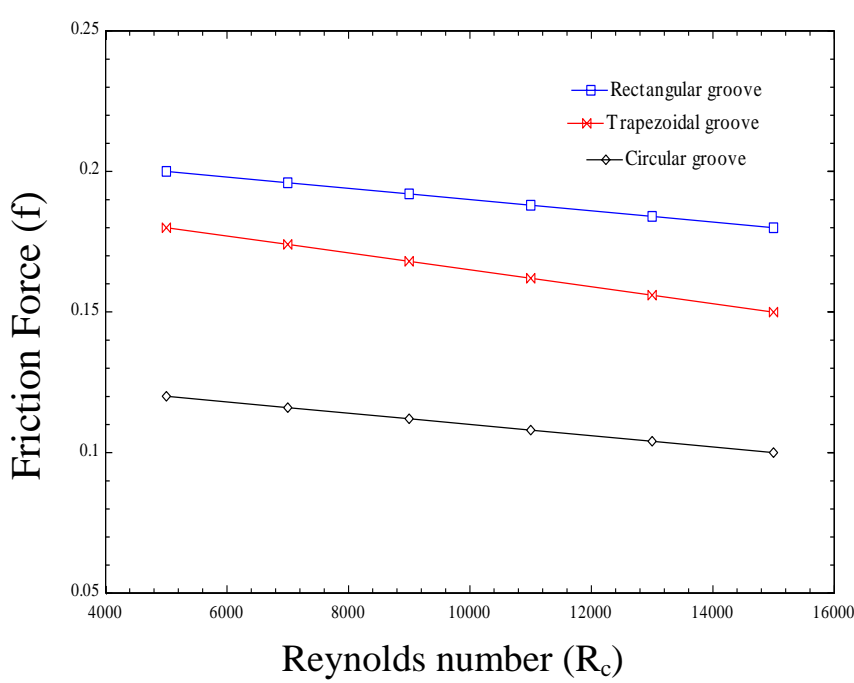

Figure (8): Variation of friction factor with Reynolds number for different grooved.

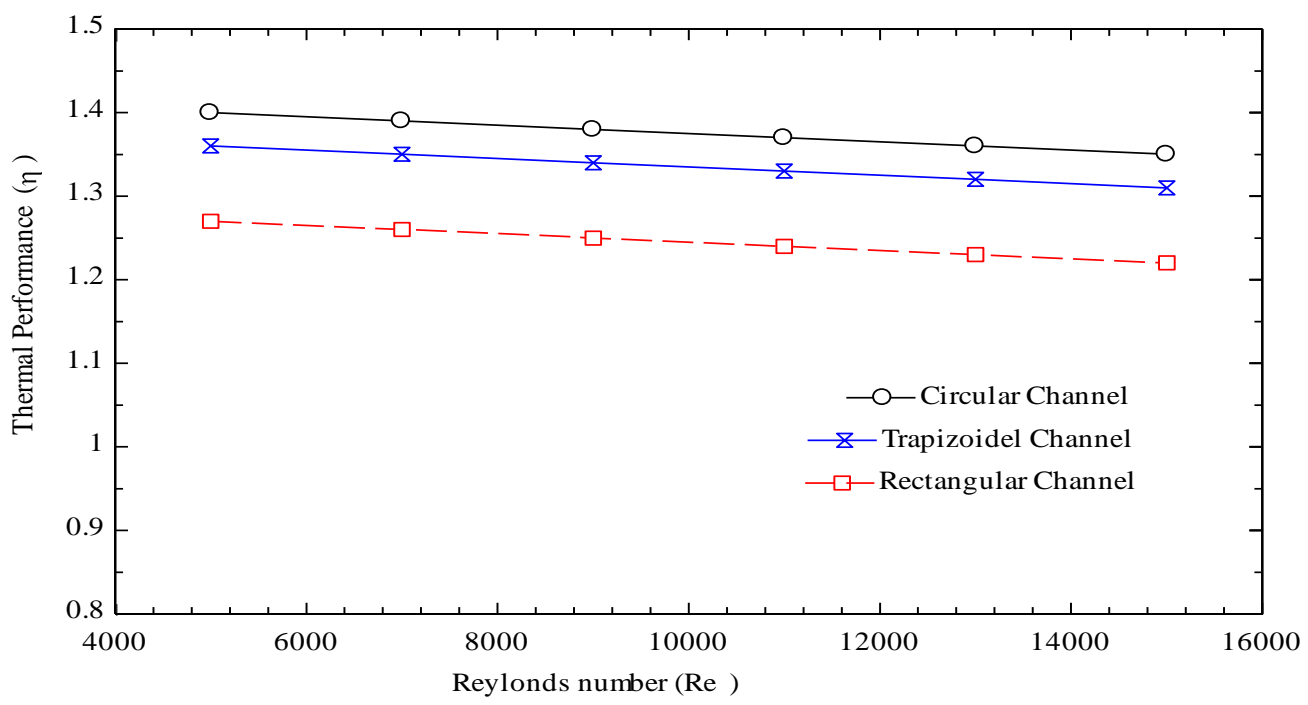

Figure (9): Comparison of thermal performance in the grooved pipe for different channel 
Figure (10- a,b and c) depicts the heat transfer coefficient variation with the axial grooved length for all configurations. Again it's found that the maximum heat transfer coefficient is in the circular geometry shape. Also the heat transfer coefficient increases with the increase of Reynolds number. The minimum heat transfer coefficient is found in rectangular grooved geometry for all values of Reynolds number. These figures present the fact that the heat transfer coefficient of the rectangular geometry is less compared with that of circular geometry shape with increasing Reynolds number. This result is similar for different Reynolds number values. Avoiding the sharp vertical corner or providing a little radius on the corner of the groove can decrease the recirculation (dead) region effect and causes good disturbances in the flow, resulting in an increase in the heat transfer rate. The rectangular groove causes more turbulence intensity in the flow because its sharp corner edges but it causes more recirculation region inside the groove. So it prevents good mixing of fluid. Thus it results in less increase in heat transfer in comparison with both circular and trapezoidal grooved tubes. In general speaking, both circular and trapezoidal grooves cause more considerable enhancement in heat transfer due to more sweeping of the surface, good flow mixing and decrease in recirculation region as mentioned before.
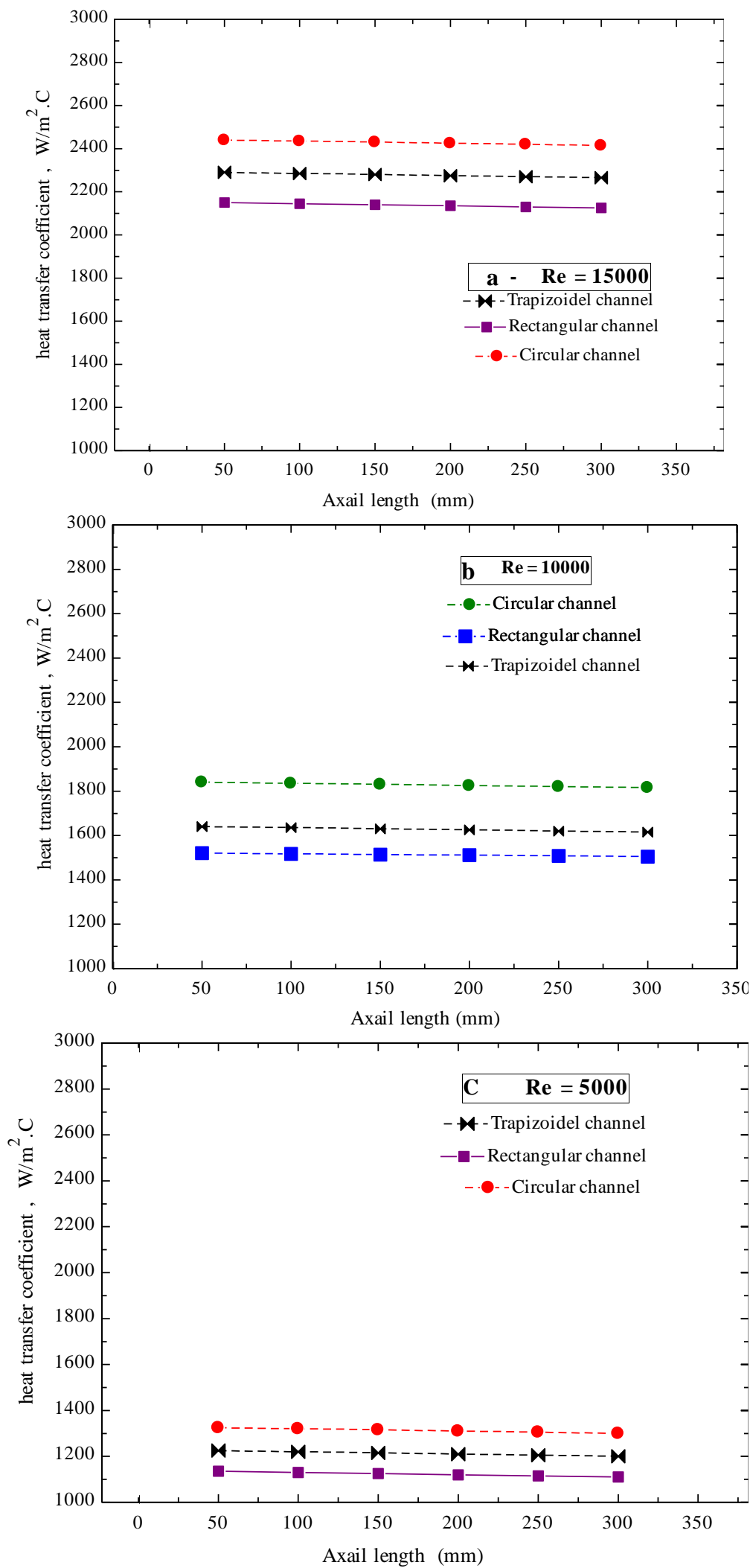

Figure (10): The variation of the heat transfer coefficient along the axial length of the heat pipe for three shapes at different values of Reynolds number at (150W) Power 
Figure (11) shows the wall temperature variation along the height of the circular groove. It is clear from the figure that the temperature difference increases with the height increase and in the same time with power input increase.

\section{5- Conclusions}

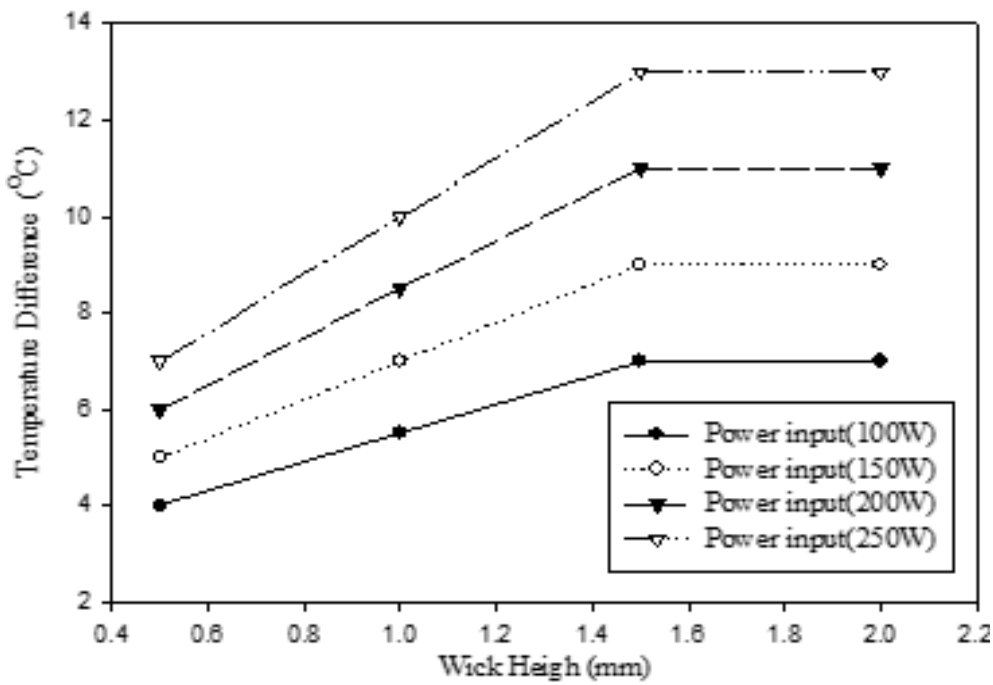

Figure (11): The variation of the wick height with the temperature difference at various power input and for circular geometry shape.

From the numerical model, the following conclusions can be extracted:

1- The heat transfer coefficient is found to be maximum in the circular shape geometry, and increases with the heat input increase.

2- The temperatures different varies with the capillary radius distribution in groove height for the three shapes.

3- The variation of friction coefficients of all grooved pipe is independed of Reynolds number but it was found that the friction in the circular groove shape is the lowest compared to the other shapes.

\section{References}

[1] M. Oomi, T. Fukumoto, T. Sotani, A heat-pipe system for cooling a desktop computer, Adv. Electron. Packaging 2(1999) 1951-1955.

[2] J.Y. San, W.C. Huang, Heat transfer enhancement of transverse ribs in circular tubes with consideration of entrance effect, Int. J. Heat Mass Transfer V(49), (2006).

[3] G.Stros, T.Rohloff, I. Catton, An experimental study of the capillary forced in the rectangular channel vs. triangular channel, ASME NHTC HTD-200(1993) 1-8.

[4] D. Khrustalev, A. Faghri, Thermal analysis of a micro heat pipe, J. Heat Transfer 116 (1994) 189-198.

[5] R.L. Webb, E.R.G. Eckert, R.J. Goldstein, Heat transfer and friction in tubes with repeated-rib roughness, Int. J. Heat Mass Transfer 14 (1971) 601-617.

[6] E.M. Sparrow, K.K. Koram, M. Charmchi, Heat transfer and pressure drop characteristics induced by a slat blockage in a circular tube, ASME J. Heat Transfer 102 (1980) 64-70.

[7] Kiml R, Magda A, Mochizuki S, Murata A, Rib-induced secondary flow effects on local circumferential heat transfer distribution inside a circular rib-roughened tube, Int. J. Heat Mass Transfer 47 (6-7) (2004) 403-412.

[8] M. Goto, N. Inoue, N. Ishiwatari, Condensation and evaporation heat transfer of R410A inside internally grooved horizontal tubes, Int. J. Refrig. 24(7)(2001)628-638.

[9] M. Goto, N. Inoue, R. Yonemoto, Condensation heat transfer of R410A inside internally grooved horizontal tubes, Int. J. Refrig. 26 (2003) 410-416. 
[10] N.K.Ghaddar, K.Z.Korczak, B.B.Mikic, A.Y.Patera, Numerical investigation of incompressible flow in grooved channels.Part 1.Stability and self-sustained oscillations,J.FluidMech.163(1986)99-127.

[11] B. Sunden, S. Trollheden, Periodic laminar flow and heat transfer in a corrugated twodimensional channel, Int. Commun. Heat Mass Transfer 16 (1989) 215-225.

[12] J.C.F. Pereira, J.M.M. Sousa, Finite volume calculations of self-sustained oscillations in a grooved channel, J. Comput. Phys. 106 (1993) 19-29.

[13]Carey,V.P., Liquid-Vapor Phase-Change Phenomena ,Washington (1992).

[14] R. Hopkins, A. Faghri, D. Khrustalev, Flat miniature heat pipes with micro Marching velocity of the capillary Meniscus in a Microchannal," J. Heat Transfer 14(2004).

[15] Reay, D.A. and Kew ,p.," Heat Pipes Theory, Design and Applications," ${ }^{\text {rd. }}$ Edition, Britain,(2006).

[16] Kreith,F.,Boehm,R.F.,Raithby,G.D. and Hollands,K.G., "Heat and Mass Transfer Handbook, " CRC Press LLC,(2000).

[17] A. Faghri, Heat Pipe Science and Technology, Taylor \& Francis, Washington, (1995), pp. 124-125.

[18] Myer K., "Mechanical engineer's Handbook: Energy and Power," Published by John

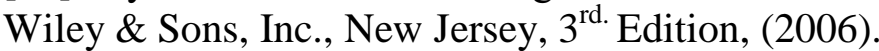

[19] Peterson, G.P. ,"An Introduction to Heat Pipes Modeling, Testing and Applications," New York,(1994).

[20] Bejan, A. and Kraus A.D., "Heat Transfer Handbook," Published by John Wiley \& Sons, Inc., Hoboken, New Jersey,(2003).

[21] Garey, V.P., liquid-vapor phase-change phenomena, Hemispher, Washington (1992).

[22] R.Hopkins, A. Faghri, D. Khrustaler, Flat miniature heat pipes with micro capillary grooves, J. Heat Transfer 121 (1999).

[23]S. chi, Heat pipe Theory and Practices: A sourcebook, Hemispher Publishing, New york, (1976) 